\title{
Investigation of the Impact Behavior of Pultruded Hybrid Composite Profiles
}

\author{
Onder Yesil (Corresponding author) \\ Department of Mechanical Engineering, Faculty of Engineering, Usak University \\ Po box 64200, Usak, Turkey \\ E-mail: onder.yesil@usak.edu.tr \\ Osman Asi \\ Department of Mechanical Engineering, Faculty of Engineering, Usak University \\ Po box 64200, Usak, Turkey \\ E-mail: osman.asi@usak.edu.tr
}

This study was supported by TUBITAK 1505 project with the number of 5150016 and partially based on a PhD. Thesis studies by Onder Yesil.

\begin{abstract}
The pultrusion process is a widely used technique for production of continuous fiber reinforced plastic profiles with constant cross-section. In some applications, requirements are demanding for profiles able to provide better thermal, acoustic insulation or mechanical properties. In such cases, hybrid pultruded profiles with certain reinforcement configuration are a possible solution. In this study, an experimental study has been carried out to investigate the impact behaviour of polymer matrix hybrid fiber reinforced I profiles. The profiles were produced as reinforced with glass-carbon fibers and polyester resin by pultrusion method. A reference profile (all-GFRP: Glass Fiber Reinforced Plastics) and six series of hybrid profiles which have different types and configuration of fiber reinforcement were tested under Izod notch impact test to assess their structural response up to failure. Izod notch impact tests were conducted according to the ASTM D 256 standard. According to the results of the experimental study; it has been found that the fibre, matrix and mat type added into the hybrid composites during the production of hybrid composite materials significantly affect the impact strength of the produced hybrid composite materials
\end{abstract}

Keywords: Pultrusion, Hybrid composite, Impact behavior, Glass fiber, Carbon fiber.

DOI: $10.7176 / \mathrm{JSTR} / 5-5-04$

\section{Pultruzyon Yöntemi ile Üretilmiş Hibrit Kompozit Profillerin Darbe Davranışlarının İncelenmesi}

\begin{abstract}
Özet
Pultruzyon işlemi, sabit kesitli sürekli elyaf takviyeli plastik profillerin üretimi için yaygın olarak kullanılan bir tekniktir. Bazı uygulamalarda daha iyi termal, akustik yalıtım veya mekanik özellikler sağlayabilen profiller için gereksinimlere ihtiyaç duyulmaktadır. Bu gibi durumlarda belirli takviye konfigürasyonuna sahip pultruzyonla üretilmiş hibrit kompozit profiller olası bir çözümdür. Bu çalışmada; polimer matrisli hibrit fiber takviyeli I profillerin darbe davranışını araştırmak için deneysel bir çalışma gerçekleştirilmiştir. Profiller cam-karbon elyaflarla takviyelendirilmiş ve polyester matrisli olarak pultruzyon yöntemi ile üretilmiştir. Bir referans profil (tamamen CTP: Cam Elyaf Takviyeli Plastik) ve farklı konfigürasyonlu elyaf takviyesine sahip altı seri hibrit profiller, İzod çentik darbe testinde deneye tabi tutulmuşlardır. İzod çentik darbe deneyleri ASTM D 256 standardına göre gerçekleştirilmiştir. Deneysel çalışmaların sonuçlarına göre; hibrit kompozit malzemelerin üretimi esnasında hibrit kompozitlere eklenen elyaf, matris ve keçe tipinin üretilmiş hibrit kompozit malzemelerin darbe dayanımını önemli ölçüde etkilediği bulunmuştur.
\end{abstract}

Anahtar Kelimeler: Pultruzyon, Hibrit kompozit, Darbe davranışı, Cam elyaf, Karbon elyaf.

26 | P a g e

www.iiste.org 


\section{Giriş}

Pultrüzyon yöntemi ile üretilen cam elyaf takviyeli polimer matrisli kompozit profiller günümüzde dünyanın pek çok ülkesinde yaygın olarak kullanılmaktadır. Özellikle inşaat, otomotiv-taşıma, boru, tank, altyapı, enerji, karayolu uygulamaları, elektrik-elektronik sanayi, belediye hizmetleri, savunma sanayi ve havacılık gibi alanlarda çok yaygın bir şekilde kullanılmaktadır. Korozyonun, hafifliğin, yüksek dayanımının önemli olduğu yerlerde daha çok tercih edilmektedirler. Kompozit malzeme kullanılarak imalatı yapılan parçaların imalatında çok farklı imalat yöntemleri bulunmaktadır. Her bir yöntemin diğerine göre kalite, dayanım ve maliyet bakımından avantajları ve dezavantajları bulunmaktadır. Pultruzyon yöntemi ile üretimi yapılan profillerin genellikle performans-maliyet ilişkisi daha iyi olmaktadır.

Elyaf takviyeli polimer matrisli kompozit malzemeler birçok mühendislik uygulamasında yaygın olarak kullanılmakla birlikte araştırmacılar tarafindan mekaniksel ve fiziksel özellikleri farklı uygulamalarla geliştirilmeye, iyileştirilmeye çalışılmakta ve bu uygulamaların etkileri araştırılmaktadır. Karbon ve cam elyafların hibritleştirilmesi kompozit malzemelerin çekme dayanımı, eğme dayanımı, elastisite modülü, rijitlik ve yapısal kararlılık gibi bazı mekanik özelliklerini iyileştirse de kopma uzaması, darbe dayanımı ve tokluk değerlerinde olumsuzluklar gözlendiği çeşitli araştırmacılar tarafindan kaydedilmiştir (Jesthi vd., 2018). Denizcilik endüstrisinde tekne ve bot yapımından balık oltasına kadar birçok alanda uygulamalara sahip olan elyaf takviyeli kompozit malzemeler sağladıkları üstün özellikleri sebebiyle tercih edilmektedir. Darbe davranışları kompozit malzemelerde araştırılması gereken bir konu olup, fark 1 hasar mekanizmaları ve bunların etkileşimi malzeme hasarına sebep olmaktadır (Sutherland, 2018).

Darbe tokluğu, malzemelerin çalışma ortamlarında maruz kalabilecekleri darbeli yüklere karşı dayanım değerinin bir ifadesi olup, sistemin yapısal kararlılı̆̆ için önem arz etmektedir. Kompozit malzemelerin darbe tokluklarını iyileştirmek maksadıyla takviye elemanları ve matris bileşenlerinin farklı modifikasyonlarının malzeme üzerindeki etkileri araştırmacıların üzerinde çalıştığı konular arasındadır. Yapılan nano büyüklükteki $\mathrm{Al}_{2} \mathrm{O}_{3}$ parçacık takviyesinin belirli oranlara kadar darbe dayanımını iyileştirdiği bilinmektedir. Ancak düşük takviye oranlarında birbirine yakın darbe tokluğu değerleri gözlemlenmiştir (Guan Shi vd., 2004). Darbe tokluğunu iyileştirme araştırmaları takviye elemanlarının ve matris bileşeninin etkilerini araştırmak üzere iki farklı yaklaşımla yapılmaktadır. Takviye elemanları gelişmiş tekstil teknolojileri kullanılarak faklı dizilim ve geometriye (dokuma, örgü, keçe vb.) sahip olacak şekilde üretilmekte ve malzemenin darbe tokluğuna etkisi incelenmektedir. İkinci yöntem ise kırılgan yapıya sahip olan termoset plastik malzemelerin çeşitli kimyasal katkı ve 1sıl işlemelerle darbe tokluğunu artırılması üzerine yapılan çalışmalardır. Matris eleman içerisine yapılan elastomer katkılarının darbe tokluğu üzerinde olumlu etkiler sağladığı yapılmış araştırmalarda görülmektedir (Carvelli vd., 2016; Li vd., 2019). Bazı plastiklerin kullanım yerine göre sahip olması beklenen önemli özelliklerden bir tanesi de yanmazlıktır. Matris içerisine yapılan alüminyum hidroksit ve magnezyum hidroksit gibi alev geciktirici katkıların ağırlıkça $\% 20$ oranında takviyesi darbe tokluğunu iyileştirmiştir (Liang, 2017). Polipropilen matris içerisine belirli ağılık oranlarında katılan çok duvarlı karbon nanotüplerin (MWCNT) yapısına bağlı olarak farklı davranışlar sergilemelerine karşın genel olarak çentik darbe tokluğunu artırmış olduğunu ifade eden çalışmalar da literatürde mevcuttur (Liang, 2018). Reçine transfer kalıplama yöntemiyle üretilen organik elyaf takviyeli epoksi matrisli kompozit malzemeler üzerinde yapılan çalışmalarda darbe tokluklarının sentetik elyaf takviyeli kompozitlere nazaran daha düşük oldukları görülmektedir (Sarıkaya, 2019).

\section{Materyal ve Metot}

Bu çalışmada; cam elyaf, karbon elyaf, cam elyaf sürekli keçe, 0/90 karbon elyaf ve cam elyaf sürekli keçe dikilerek elde edilmiş hibrit keçeler kompozit profil üretiminde takviye elemanları olarak, izofitalik polyester reçine ise matris malzemesi olarak kullanılmıştır. Sabit en kesitli kompozit profillerin üretiminde, sağlamış olduğu kolaylık ve üstünlüklerden dolayı en yaygın kullanılan, pultruzyon üretim yöntemi tercih edilmiştir. Farklı oryantasyon ve takviye elemanı konfigürasyonuna sahip toplamda yedi farklı tipte kompozit I profiller üretilmiştir. Çizelge 1'de üretimi yapılan profillerin konfigürasyonu ve spesifikasyonları verilmiştir. 
Çizelge 1. Üretimi yapılan kompozit profillere ait konfigürasyon ve spesifikasyonlar

\begin{tabular}{|c|c|c|c|}
\hline $\begin{array}{c}\text { Numune } \\
\text { tipi }\end{array}$ & Elyaf tipi & Keçe tipi & Reçine tipi \\
\hline Tip 1 & Cam elyaf fitil & Cam elyaf sürekli keçe $(1,2,3,4,5,6,7)$ & Polyester \\
\hline Tip 2 & Cam elyaf fitil & Cam-karbon hibrit keçe $(1,2,3,4,5,6,7)$ & Polyester \\
\hline Tip 3 & Cam elyaf fitil & $\begin{array}{l}\text { Dış keçe: cam elyaf sürekli keçe }(1,2,4,5) \\
\text { İç keçe: cam-karbon hibrit keçe }(3,6,7)\end{array}$ & Polyester \\
\hline Tip 4 & Cam elyaf fitil & $\begin{array}{l}\text { Dış keçe: cam-karbon hibrit keçe }(1,2,4,5) \\
\text { İç keçe: cam elyaf sürekli keçe }(3,6,7)\end{array}$ & Polyester \\
\hline Tip 5 & $\begin{array}{l}\text { Cam-karbon elyaf } \\
\text { fitil cam-karbon } \\
\text { oranı: } 3 / 5\end{array}$ & Cam elyaf sürekli keçe $(1,2,3,4,5,6,7)$ & Polyester \\
\hline Tip 6 & $\begin{array}{l}\text { Cam-karbon elyaf } \\
\text { fitil cam/karbon } \\
\text { oranı: } 3 / 5\end{array}$ & Cam-karbon hibrit keçe $(1,2,3,4,5,6,7)$ & Polyester \\
\hline Tip 7 & $\begin{array}{l}\text { Cam-karbon elyaf } \\
\text { fitil cam/karbon } \\
\text { orant: } 3 / 1\end{array}$ & $\begin{array}{l}\text { Dış keçe: cam elyaf sürekli keçe }(1,2,4,5) \\
\text { İç keçe: cam-karbon hibrit keçe }(3,6,7)\end{array}$ & Polyester \\
\hline
\end{tabular}

I profil üç farklı bölgeye ayrılmış ve sırasıyla $\mathrm{A}, \mathrm{B}, \mathrm{C}$ bölgesi olarak isimlendirilmiştir. I profillere ait konfigürasyon şeması, takviye elamanlarının, keçelerin numaraları ve konumlandırılması Şekil 1'de verilmiştir. Üretilen kompozit malzemelerin çentik darbe deneyleri, plastiklerin ve polimer matrisli kompozit malzemelerin darbe dayanımlarının tespitinde çok yaygın olarak kullanılan, ASTM D 256 standardına göre İzod çentik darbe deney numuneleri ile yapılmıştır. Numuneler üretilen profillerin C bölgesinden ASTM D 256 standardına göre kesilerek hazırlanmıştır. Cam elyaf fitiller 4800 Tex, karbon elyaf fitiller 1600 Tex olacak şekilde takviye elemanları olarak kullanılmıştır. Kullanılan takviye elemanlarına ait fotoğraflar Resim 1'de verilmiştir.

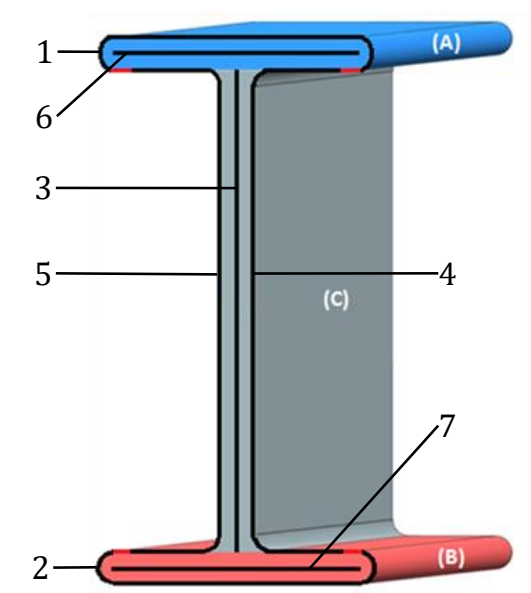

Şekil 1. Üretilen I profillere ait konfigürasyon şeması 


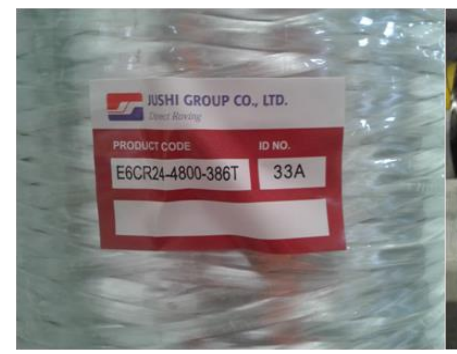

(a)

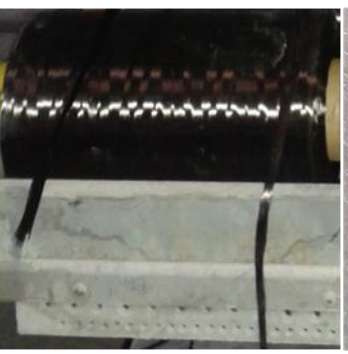

(b)

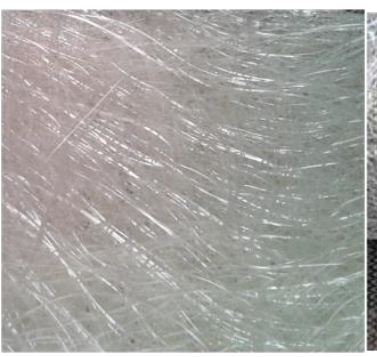

(c)

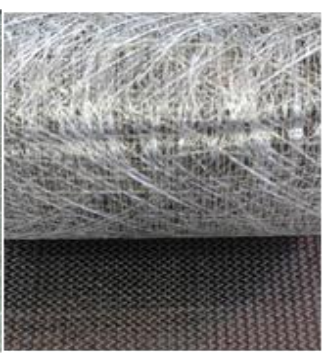

(d)

Resim 1. Kompozit malzemelerin üretiminde kullanılan takviye elmanları (a) cam elyaf fitil, (b) karbon elyaf fitil, (c) cam elyaf sürekli keçe, (d) cam-karbon hibrit keçe

Şarj (reçine, matris karışımı) hazırlama işleminde reçine içerisine kalsit $\left(\mathrm{CaCO}_{3}\right)$ katı dolgu ve kürleşme işlemini hızlandırmak maksadıyla peroksan reaksiyon hızlandırıcılar belirli miktarlarda (\% 40 kalsit, \%1,5 peroksan) eklenerek karıştırılmıştır. Hazırlanan şarj pultruzyon hattındaki reçine havuzuna dökülmüştür. Çizelge 1 'de verilmiş olduğu haliyle üretim konfigürasyonuna göre elyaf fitiller ve keçeler takviye elemanı olarak üretim hattına hazırlanmış, ardından reçine havuzunda ıslatılmış ve şekillendirme kılavuzları yardımıyla ısıtılan kalıba yönlendirilmiştir. Isıl çift kullanılan bir elektronik devre yardımıyla sıcaklıkları kontrol edilen ve elektrikli dirençlerle 1sıtılan kalıbın giriş, orta ve çıkış bölgeleri sırasıyla; $93{ }^{\circ} \mathrm{C}, 146^{\circ} \mathrm{C}$ ve $157^{\circ} \mathrm{C}$ sıcaklığa sahip olacak şekilde gerekli düzenlemeler yapılmıştır.

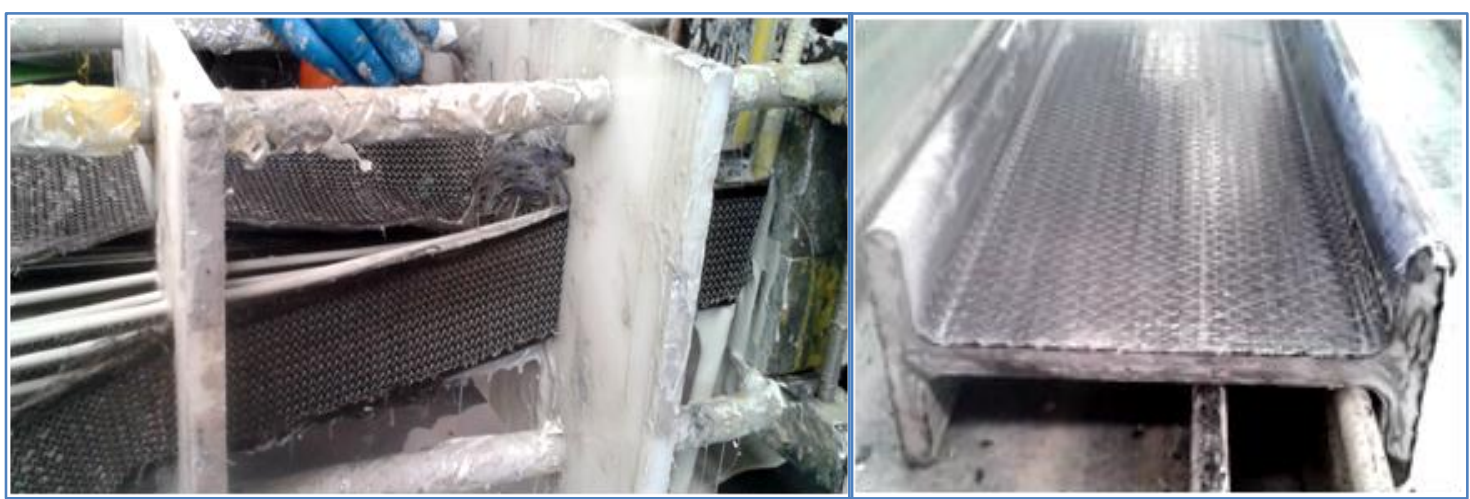

Resim 2. Tip 6 numune konfigürasyona ait üretim fotoğrafları

Kalıbın giriş bölgesi sıcaklığı kompozit malzemenin şekillendirilebilmesi ve bölgesel ani kürleşmelerin önüne geçebilmek için diğer bölgelere nazaran daha düşük sıcaklığa ayarlanmıştır. Profil çekme hızı 27 $\mathrm{cm} /$ dak olacak şekilde pultruzyon yöntemi ile üretim prosesi gerçekleştirilmiştir. Resim 2'de Tip 6 numune konfigürasyonuna ait üretim fotoğrafları verilmiştir.

Çentik darbe deneyi, darbe yüküne maruz kalan malzemenin çentik darbe tokluk değerlerini ölçmek maksadıyla yapılan bir deneydir. Bu çalışmada; ASTM D 256 standardına göre hazırlanan numunelerin İzod çentik darbe deneyleri 5.5 J'lük çekiç ile oda sıcaklıklarında yapılmıştır.

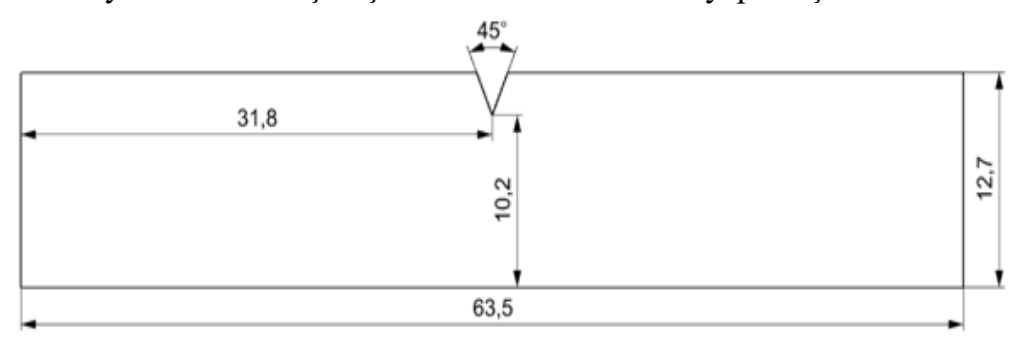

Şekil 2. İzod çentik darbe deney numunesi ölçüleri ve şematik görünümü

Şekil 2'de verilen boyutlarda I profilin C bölgesinden $90^{\circ}$ (enine) doğrultuda beşer adet numune kesilerek hazırlanmıştır. Kesilen numunelere $2,5 \mathrm{~mm}$ derinlik ve $0,25 \mathrm{~mm}$ uç radyusuna sahip olacak şekilde $45^{\circ}$ açıya sahip V çentikler açılmıştır. Çentik açılmış bazı deney numunelerine ait fotoğraflar Resim 3' de verilmiştir. Hazırlanan numuneler Resim 4'de verilen İzod çentik darbe deney cihazı ile darbe testine tabi tutulmuştur. 

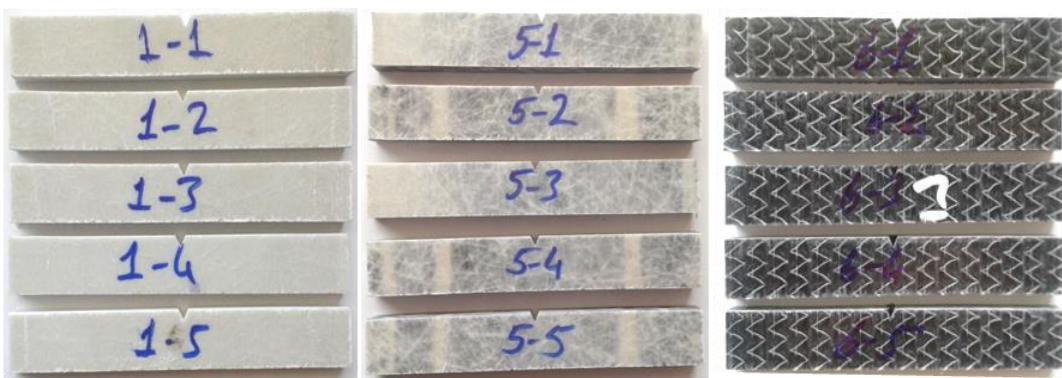

Resim 3. Üretimi yapılan Tip 1, Tip 5, Tip 6 numune konfigürasyonuna ait çentik darbe deney numuneleri

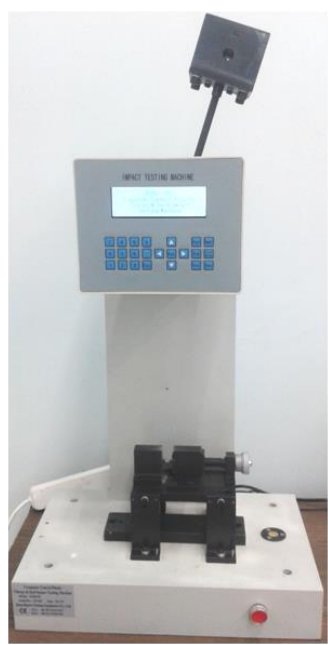

Resim 4. İzod çentik darbe deneyi cihazı

Çentik darbe deneyi yapılan numunelerde, KV çentik darbe işi Eşitlik 1 ile $a_{k}$ çentik darbe tokluğu Eşitlik 2 kullanılarak hesaplanmaktadır.

$$
\begin{gathered}
K V=m g(H-h) \\
a_{k}=10^{3} * \frac{K V}{S_{0}}
\end{gathered}
$$

Burada;

$\mathrm{KV}$ : çentik darbe işi $(\mathrm{J})$

H: çekicin bırakıldığ 1 yükseklik (m)

h: çekicin numuneyi kırdıktan sonra çıktığg yükseklik (m)

m: çekiç kütlesi (kg)

$\mathrm{g}$ : yer çekimi ivmesi $\left(\mathrm{m} / \mathrm{s}^{2}\right)$

$\mathrm{S}_{0}$ : kirılma kesit alanı $\left(\mathrm{mm}^{2}\right)\left(\mathrm{S}_{0}=\mathrm{bxt}\right)$

b: numune eni (mm)

t: numune kalınlığı $(\mathrm{mm})$

$\mathrm{a}_{\mathrm{k}}$ : çentik darbe tokluğudur $\left(\mathrm{kJ} / \mathrm{m}^{2}\right)$.

\section{Deneysel Bulgular ve Tartışma}

Yapılan İzod çentik darbe deneyi sonuçları Çizelge 2'de verilmiştir. Şekil 3'de numunelerin çentik darbe tokluk değerlerinin karşılaştırılması verilmiştir. 
Çizelge 2. Üretimi yapılan kompozit profillerden elde edilen $90^{\circ}$ enine numunelerin İzod darbe deneyi sonuçları

\begin{tabular}{|c|c|c|}
\hline $\begin{array}{c}\text { Numune } \\
\text { tipi }\end{array}$ & $\begin{array}{c}\text { Çentik darbe işi (KV) } \\
(\mathrm{J})\end{array}$ & $\begin{array}{c}\left.\text { Çentik darbe tokluğu ( } a_{k}\right) \\
\left(\mathrm{kJ} / \mathrm{m}^{2}\right)\end{array}$ \\
\hline Tip 1 & 1.33825 & 20.25075 \\
\hline Tip 2 & 2.64225 & 39.8495 \\
\hline Tip 3 & 1.6575 & 24.94425 \\
\hline Tip 4 & 2.80775 & 42.722 \\
\hline Tip 5 & 1.0345 & 15.47325 \\
\hline Tip 6 & 1.57125 & 24.8955 \\
\hline Tip 7 & 1.407 & 21.7255 \\
\hline
\end{tabular}

Yapılan deneysel çalışmanın sonuçlarına göre, genel olarak cam-karbon elyaf 0/90 oryantasyona sahip hibrit keçelerin dış keçeler $(1,2,4,5)$ olarak kullanımının çentik darbe tokluğunu artırdığı belirlenmiştir. En yüksek çentik darbe tokluğu sergileyen Tip 4 numunelerde cam-karbon elyaf $0 / 90$ hibrit keçelerin dış keçe olarak kullanımının etkisi açıkça Şekil 3'de görülmektedir. Cam elyaf takviyeli kompozitlerin dış keçelerinin cam-karbon elyaf $0 / 90$ hibrit keçeler ile takviye edilmesinin darbe tokluğunu Tip 1 numunelere nazaran \% 111 oranında artırma yönünde olumlu etki yaptı̆̆ belirlenmiştir. İç keçelerinde $(3,6,7)$ cam-karbon elyaf 0/90 hibrit keçeler kullanılan cam elyaf takviyeli Tip 3 numunelerin darbe tokluğunda \% 23.2 oranında artış sağlanmıştır. Ancak sslanma problemleri ve elyaflarla bağlanma durumundan kaynaklı olarak, darbe tokluğundaki bu artışın dış keçeleri hibrit olan numunelere göre daha düşük olduğu kaydedilmiştir.

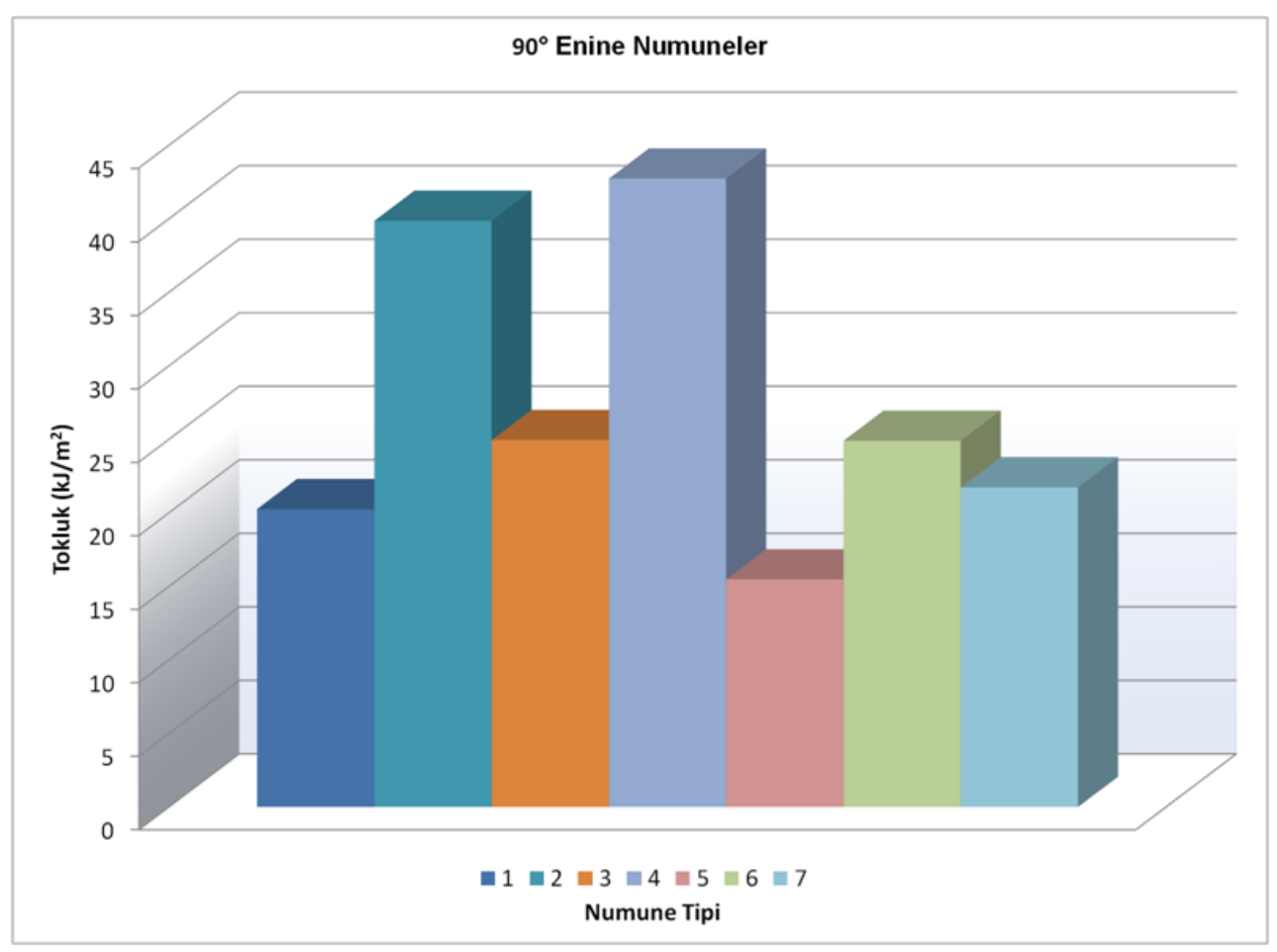

Şekil 3. Çentik darbe tokluklarının numune tipine göre kıyaslaması

İç ve dış keçeleri $(1,2,3,4,5,6,7)$ cam-karbon elyaf 0/90 hibrit keçe kullanılarak üretilen Tip 2 numunelerin, iç keçelerinin hibrit olmasından ve bahsedilen olumsuzluklardan dolayı yalnızca dış keçeleri hibrit keçe olan Tip 4 numunelere nazaran çentik darbe tokluklarında $\% 6.72$ oranında düşüş görülmüştür. Karbon-cam elyaf fitil takviyesi ve cam elyaf keçeler kullanılarak üretilen Tip 5 numunelerin çentik darbe tokluğu değerlerinin cam elyaf takviyeli Tip 1 numunelerden $\% 23.6$ daha düşük değerler sergilediği belirlenmiştir. Karbon elyafların ince filamentlerinden dolayı reçine nüfuziyetinin güçlüğü ve bağlanmasının zorluğunun bu sonuca neden olduğu düşünülmektedir. Tip 6 numunelerin elyaf fitil takviyesi oranının Tip 5 numunelerle aynı olmasına karşın, yapılan hibrit keçe 
takviyesinin olumlu etkisinden kaynaklı olarak çentik darbe tokluğu değerlerinin Tip 5 numunelere nazaran \% 60.9 oranında artış sağladığ 1 belirlenmiştir. Tip 6 numunelerde karbon elyaf fitil takviyesinin yüksek olmasına karşın hibrit keçe kullanımı darbe tokluğu değerlerini Tip 1 numunelere nazaran \% 22.9 oranında artırmıştır. Tip 7 numunelerin karbon elyaf fitil takviyesi oranı Tip 5 ve Tip 6 ya göre \% 66.66 daha az ve iç keçeler $(3,6,7)$ hibrit keçe olacak şekilde üretilmiştir. Karbon elyaf fitil takviyesinin az olması ve iç keçelerin hibrit olmasından kaynaklı olarak Tip 7 numunelerin darbe tokluğu değerleri Tip 5'e nazaran \% 40.4 artış gösterirken Tip 1 cam elyaf takviyelilere göre \% 7.3 artış sergilemiştir.

Yapılan çalışma sonucunda; üretimi yapılan kompozit numunelerin çentik darbe tokluğu değerleri yüksekten düşüğe doğru sırasıyla Tip 4, Tip 2, Tip 3, Tip 6, Tip 7, Tip 1 ve Tip 5 numuneleri şeklindedir. Hibrit keçe takviyesi oranının belirli bir değerin üzerinde olmasının çentik darbe tokluğunu olumsuz etkilediği ve bununla birlikte karbon elyaf fitil takviye oranının yüksek olduğu numunelerde bu olumsuzluğun daha da belirgin değerlerde olduğu görülmektedir. Resim 5 'te deney numunelerine ait kırılma yüzeylerinin fotoğrafları verilmiştir.

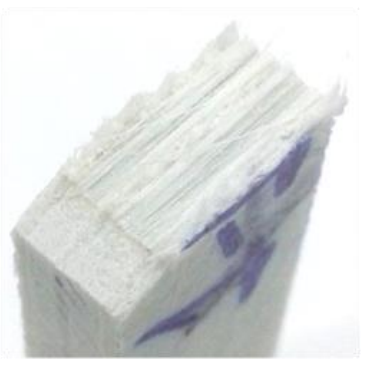

Tip 1

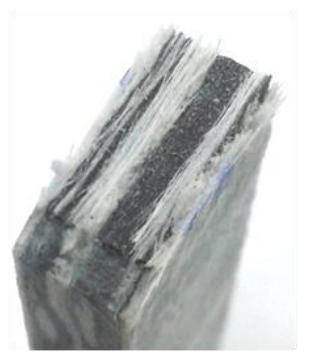

Tip 5

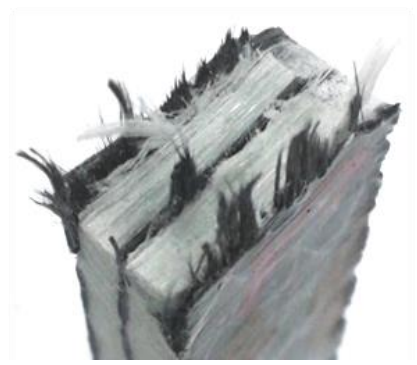

Tip 2

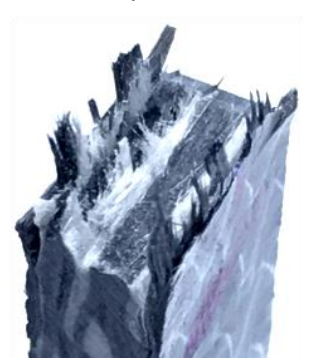

Tip 6

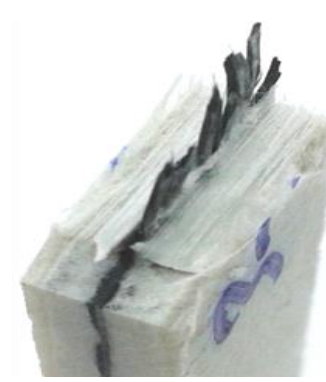

Tip 3

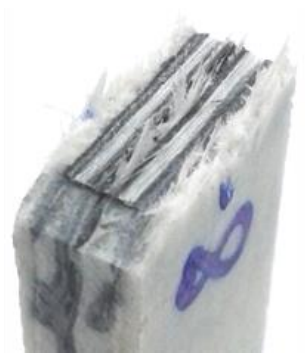

Tip 7

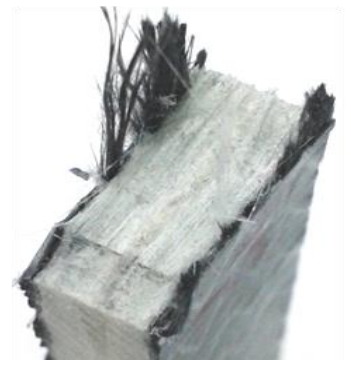

Tip 4

Resim 5. İzod çentik darbe deney numunelerine ait kırılma yüzeyleri

Karbon elyaf fitil takviyeli numunelerde karbon takviyesi oranına bağlı olarak darbe tokluğunda düşüşler görülmüştür. Tip 7 numunelerde ağırlıkça \% 25 karbon elyaf fitil takviyesi, Tip 5 ve Tip 6 numunelerde ağırlıkça \% 62.5 karbon elyaf fitil takviyesi yapılmıştır. Karbon elyaf fitil takviyesi oranına bağlı olarak darbe tokluğunda meydana gelen değişim grafiği Şekil 4'de verilmiştir.

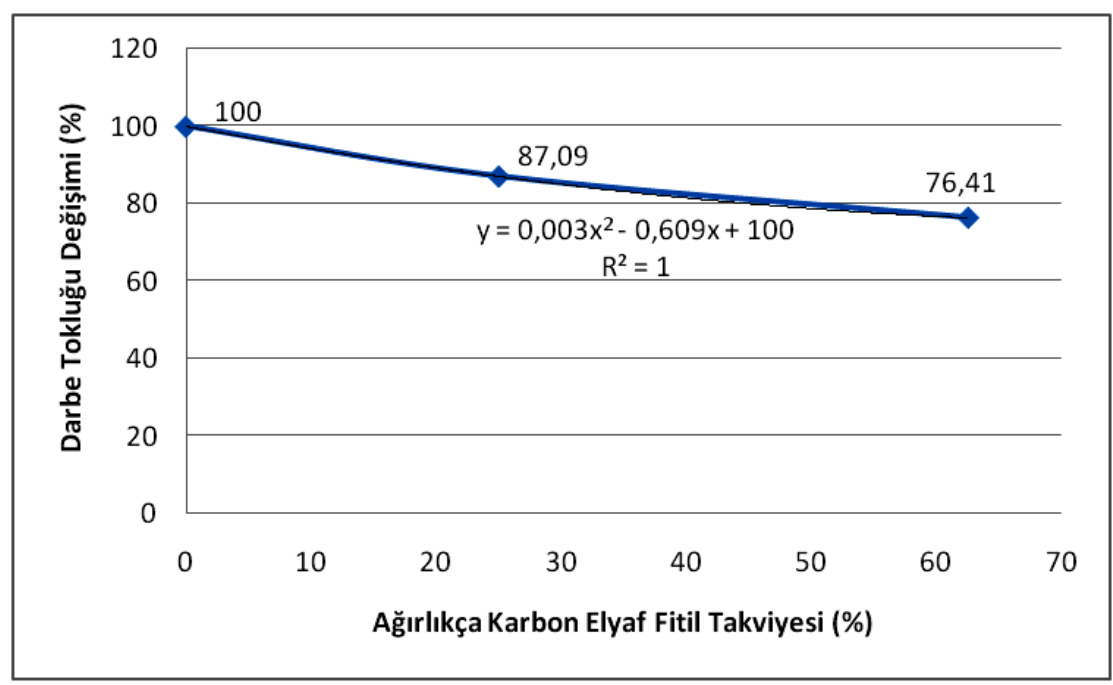

Şekil 4. Çentik darbe tokluklarının karbon elyaf fitil takviyesi oranına göre değişimi

32 | P a g e 
Şekil 4'de verilen $\mathrm{R}^{2}$ belirlilik katsayısı olarak tanımlanmakatdır. $\mathrm{R}^{2}$ değeri; eldeki noktasal verilere uydurulan regresyon denkleminin noktasal verilerle olan doğruluğunu gösteren bir ifadedir.

\section{Sonuçlar}

$\mathrm{Bu}$ çalışmada; cam elyaf fitil, karbon elyaf fitil, cam elyaf sürekli keçe, 0/90 karbon elyaf ve cam elyaf hibrit keçenin farklı oryantasyon ve konfigürasyona sahip olacak şekilde kullanılması ile pultruzyon yöntemiyle üretilen polyester matrisli kompozit I profillerin İzod çentik darbe toklukları deneysel olarak incelenmiş ve aşağıdaki sonuçlara ulaşılmıştır:

i. $\quad$ Üretimi yapılan numunelerin çentik darbe toklukları yüksekten düşüğe doğru sırasıyla; Tip 4, Tip 2, Tip 3, Tip 6, Tip 7, Tip 1 ve Tip 5 numuneleri olduğu tespit edilmiştir.

ii. Cam elyaf takviyeli kompozit malzemelerin dış keçelerinin hibrit keçe kullanılarak üretilmesi durumunda (Tip 4) cam elyaf takviyeli kompozit malzemelere ( Tip 1) nazaran çentik darbe tokluğunda \% 111 oranında artış sağladığı görülmüştür. Hibrit keçenin dış keçe olarak kullanılması bütün numune konfigürasyonlarında darbe tokluğunu artırmaktadır.

iii. Hibrit keçenin iç keçe olarak kullanılması cam elyaf takviyeli kompozit malzemelerin (Tip 3) darbe tokluğunda \% 23.2 oranında artış sağlanmasına karşın bütün keçelerde hibrit keçe kullanılması durumunda (Tip 2) iç keçelerin darbe tokluğunu yalnız dış keçeleri hibrit (Tip 4) olan numunelere göre \% 6.72 oranında düşürdüğü tespit edilmiştir. Hibrit keçeleri iç keçe olarak belirli karbon takviyesinin üzerinde kullanmak düşük de olsa çentik darbe tokluğunu olumsuz etkilemektedir.

iv. Karbon elyaf fitil takviyesinin yapıldığ 1 numunelerin tamamında (Tip 5, Tip 6, Tip 7) karbon elyaf fitil takviyesi cam-karbon hibrit keçenin aksine darbe tokluğunu düşürmüştür. Aynı keçe konfigürasyonuna sahip olmasına karşın karbon elyaf fitil takviyesi yapılan numunelerdeki darbe tokluğu değerleri kıyaslandığında düşüş oranları; Tip 5-Tip 1 \% 23.59, Tip 6-Tip 2 \% 37.53, Tip 7- Tip $3 \% 12.91$ şeklindedir. Tip 7 numunelerde karbon elyaf fitil takviyesi oranı Tip 5 ve Tip 6'ya göre daha düşük olmasından kaynaklı olarak darbe tokluğu değerindeki düşüş daha az olmuştur. Bu durum; karbon elyaf fitil takviyesi oranındaki artışın çentik darbe tokluğunu ters orantılı olarak düşürdüğünü göstermekle birlikte ilişki lineer değildir.

\section{Kaynaklar}

Carvelli, V., Betti, A., Fujii, T. (2016). Fatigue and Izod impact performance of carbon plain weave textile reinforced epoxy modified with cellulose microfibrils and rubber nanoparticles, Composites: Part A, 84, 26-35.

Jesthi, D. K., Mandal, P., Rout, A. K., Nayak, R. K. (2018). Effect of carbon/glass fiber symmetric inter-ply sequence on mechanical properties of polymer matrix composites, Procedia Manufacturing, 20, 530-535.

Li, F., Gao, Y., Jiang W. (2019). Design of high impact thermal plastic polymer composites with balanced toughness and rigidity: Toughening with one phase modifier, Polymer, 170, 101-106.

Liang, J.Z. (2017). Impact fracture toughness and flow properties of polypropylene composites, Polymer Testing, 60, 381-387.

Liang, J.Z., Zou, S.Y., Du, Q. (2018). Impact and flexural properties of polypropylene composites reinforced with multi-walled carbon nanotubes, Polymer Testing, 70, 434-440.

Shi, G., Zhang, M. Q., Rong, M. Z., Wetzel, B., Friedrich, K. (2004). Sliding wear behavior of epoxy containing nano- $\mathrm{Al}_{2} \mathrm{O}_{3}$ particles with different pretreatments, Wear, 256, 1072-1081.

Sutherland, L.S. (2018). A review of impact testing on marine composite materials: Part I - Marine impacts on marine composites, Composite Structures, 188, 197-208.

Sarkaya, E., Çallioğlu, H., Demirel, H. (2019). Production of epoxy composites reinforced by different natural fibers and their mechanical properties, Composites Part B, 167, 461-466. 